\title{
Lymphocytic tumor necrosis factor receptor superfamily co-stimulatory molecules in the pathogenesis of atherosclerosis
}

\author{
Esther Smeets ${ }^{\mathrm{a}}$, Svenja Meiler ${ }^{\mathrm{a}}$, and Esther Lutgens ${ }^{\mathrm{a}, \mathrm{b}}$
}

\begin{abstract}
Purpose of review
The role of lymphocytes in the chronic inflammatory disease atherosclerosis has emerged over the past decade. Co-stimulatory molecules of the heterogeneous tumor necrosis factor receptor superfamily play a pivotal role in lymphocyte activation, proliferation and differentiation. Here we describe the immune modulatory properties and mechanisms of four tumor necrosis factor receptor superfamily members in atherosclerosis.
\end{abstract}

\section{Recent findings}

CD40/CD40L, OX40L/OX40, CD70/CD27 and CD137/CD137L are present in human atherosclerotic plaques and have shown strong immune modulatory functions in atherosclerosis, resulting in either atherogenic or atheroprotective effects in mouse models of atherosclerosis.

\section{Summary}

Insight into the immune modulatory mechanisms of co-stimulatory interactions in atherosclerosis can contribute to clinical exploitation of these interactions in the treatment of cardiovascular disease.

\section{Keywords}

adaptive immune system, atherosclerosis, co-stimulatory molecules, lymphocytes, tumor necrosis factor receptor superfamily

\section{INTRODUCTION}

Atherosclerosis is a chronic inflammatory disease of the arterial wall. Injurious stimuli including shear stress and modification of LDL and its subendothelial deposition activate the endothelium [1,2"']. Subsequently, inflammatory cells of both the innate and adaptive immune system are attracted and infiltrate into the subendothelial space where atherosclerotic plaques arise via intertwined immunological interactions between immune cells, endothelial cells, platelets and smooth muscle cells [3"'].

\section{THE ADAPTIVE IMMUNE SYSTEM IN ATHEROSCLEROSIS}

The role of the innate immune system in atherosclerosis has long been established. In the early 1990s, the contribution of the adaptive immune system was considered as T-lymphocytes and anitgen presenting cells (APCs) were found in close proximity within the atherosclerotic plaque $\left[1,2^{-"}\right]$. Studies in animal models indeed proved lymphocytes to play a major role in atherosclerosis. For example, $C d 4^{-1-}$ $A$ poe $^{-/-}$mice show less atherosclerotic plaques in the aortic root and adoptive transfer of $\mathrm{CD}^{+} \mathrm{T}$ cells into atherosclerosis-prone SCID Apoe $e^{-/-}$mice aggravates atherogenesis in an interferon (IFN) $\gamma$-associated manner $[4,5]$. T lymphocytes recognize epitopes on the apoB100 unit of native LDL, which supports the production of IgG to oxLDL by B cells [6]. Lymphocytes are also present in aortic tertiary lymphoid organs in very advanced atherosclerosis, in which they are considered to serve as a site for local responses against plaque antigens [7].

The divergent effects of $\mathrm{B}$ cells on atherosclerosis are attributed to subset-specific effects. B1a B cells, mainly present in peritoneal cavities,

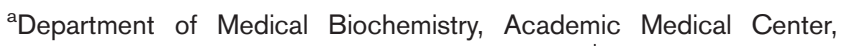
Meibergdreef, Amsterdam, The Netherlands and 'bnstitute for Cardiovascular Prevention (IPEK), Ludwig-Maximilians University, Munich, ,Germany

Correspondence to Esther Lutgens, MD, PhD, Experimental Vascular Biology, Deptartment of Medical Biochemistry, Meibergdreef 9, 1105 AZ Amsterdam, The Netherlands. Tel: +31 205663380; fax: +31 206915519; e-mail: E.Lutgens@amc.uva.nl

Curr Opin Lipidol 2013, 24:518-524

DOI:10.1097/MOL.0000000000000025 


\section{KEY POINTS}

- The adaptive immune systems impacts atherogenesis.

- TNFRSF family of co-stimulators regulates immune cell activation in the context dependent manner.

- Various members of the TNFRSF family are known atherogenic or atheroprotective factors.

- Targeting TNFRSF members may enable specific immunomodulation in atherosclerosis.

secrete atheroprotective natural IgM antibodies against oxidation-specific epitopes of LDL, thereby preventing oxLDL uptake by macrophages via their scavenger receptors and their subsequent activation $[8,9]$. Conventional B2 B cells undergo isotype switching and as such are capable of secreting different immunoglobulin isotypes in addition to IgM. B2 B cells have been shown atherogenic by studies using depleting monoclonal CD20-antibodies or adoptive transfer of B2 B cells in $A p o e^{-/-}$and $\mathrm{Ldlr}^{-/-}$mice $[10,11]$. Association between B2 B cell secreted IgG and atherosclerosis has been proposed by some, but not all, articles, as well as B2 B cellinduced $\mathrm{T}$ cell activation either through antigen presentation or cytokine secretion [12-14].

Co-stimulatory molecules tightly regulate the interactions among $\mathrm{T}$ cells, $\mathrm{B}$ cells and dendritic cells and their subsequent immune cell activation or modulation. Three signals are required for activation of naïve T or B cells (and other APCs such as dendritic cells and macrophages): the first signal is the binding of the T-cell receptor (TCR) or B-cell receptor (BCR) to an antigen, the second signal is provided through co-stimulatory molecules and the third signal through cytokines secreted by cells carrying the co-stimulatory molecules [15].

The engagement of co-stimulatory molecules on the surface of mature APCs to their counter receptors on T cells is required for proliferation and escape from anergy. Primed T cells are a heterogeneous group of cells differentiated into one of the T-cell subsets based on encountered APC-secreted cytokine profile: T-helper $\mathrm{CD}^{+}{ }^{+}$(with $\mathrm{TH} 1$, Тн2, Тн17 subprofiles), cytotoxic $\mathrm{CD}^{+}$cells and regulatory $\mathrm{T}$ cells [16].

Although the effects of the different co-stimulatory molecules are well established, the role of the different co-stimulatory pathways during the pathogenesis of atherosclerosis still needs to be fully elucidated. In this review, we will summarize the role of the tumor necrosis factor receptor superfamily (TNFRSF) members in atherosclerosis, and highlight the most important findings.

\section{TUMOR NECROSIS FACTOR RECEPTOR} SUPERFAMILY

In atherosclerosis, several members of the TNF (receptor) superfamily (such as CD40, Ox40, CD137, GITR, CD30, TNF-related apoptosis-inducing ligand and CD27) have been studied in the context of atherosclerosis (Table 1) + indicated refs. [17",18-35,36"',37-41]. In general, the expression of these molecules is enhanced upon engagement of an antigen with the TCR or BCR.

Most TNFRSF members lack intrinsic activity and require downstream adaptor proteins to induce intracellular signaling, TNFR-associated factors (TRAFs). TRAFs are recruited to the cytoplasmic tail of the trimeric TNFRs and engage with the conserved TRAF domain [41]. Until today, seven distinct TRAF molecules have been identified that interact with TNFRSF, of which five are implicated in atherosclerosis in various cellular environments: TRAF1, 2, 3, 5 and 6 [42]. Depending on cell type, environmental conditions and TRAF-binding site different downstream signaling pathways are initiated [43].

Several studies have revealed the effects of the different TRAF molecules in atherosclerosis, but the role of the different individual TNFRSFTRAF interactions is still under investigation. Endothelial specific Traf6 ${ }^{-1-} /$ Apoe $^{-/-}$mice showed reduced atherosclerosis, whereas myeloid cellspecific TRAF6-deficient Apoe ${ }^{-/-}$mice developed accelerated atherosclerosis [44]. $\mathrm{Traf1}^{-/-} / \mathrm{Ldlr}^{-/-}$ mice developed smaller atherosclerotic lesions because of impaired monocyte migration and adhesion to the endothelium [45"']. TRAF5 is atheroprotective, as shown by $\mathrm{Traf5}^{-1-} / \mathrm{L} d \mathrm{ll} \mathrm{r}^{-1-}$ mice [46]. TRAF3 serves as an inhibitor for TRAF2/5 nuclear factor $(\mathrm{NF}) \kappa \mathrm{B}$ activation upon stimulation of various TNFRSF members [47]. TRAF2 and TRAF3 upregulation is associated with shear stress $[48,49]$.

The most dominant outcome of TNFRSF-TRAF signaling is $\mathrm{NF}_{\kappa} \mathrm{B}$ and mitogen-activated protein kinase (MAPK) activity, which mediates activation, proliferation and the production of proinflammatory cytokines and adhesion molecules [41,42].

In this review, we will discuss the contribution of CD40/CD40L, OX40/OX40L, CD27/CD70 and CD137/CD137L to atherogenesis in detail, as these TNFRSF members are well studied and are considered promising candidates for therapy in atherosclerosis.

\section{CD40/CD40L}

The CD40/CD40L axis is one of the best-studied costimulatory pathways. CD40L, also known as CD154 or TNFSF5, is expressed on various cell types, both immune cells and nonhematopoietic cells, particularly $\mathrm{CD}^{+} \mathrm{T}$ cells and platelets [21]. CD40-CD40L 
Table 1. TNFRSF in human and mouse atherosclerosis

\begin{tabular}{|c|c|c|c|}
\hline Ligand & Receptor & Mouse & Human \\
\hline CD40L & CD40 & $\begin{array}{l}\text { Atherogenic - shown by administration } \\
\text { of neutralizing antibodies to } \mathrm{CD} 4 \mathrm{OL} \text {, } \\
\mathrm{Cd} 40 \mathrm{Ol} \text { genetically deficient mice, } \\
\mathrm{Cd} 40^{-/-} \text {mice [18-21] }\end{array}$ & $\begin{array}{l}\text { Expression of } \mathrm{CD} 4 \mathrm{O}(\mathrm{L}) \text { in atherosclerotic } \\
\text { lesion [22] }\end{array}$ \\
\hline
\end{tabular}

\begin{tabular}{|c|c|c|c|}
\hline & & & $\begin{array}{l}\text { Polymorphisms in CD40 gene correlate with } \\
\text { unstable coronary plaques and risk of } \\
\text { coronary plaque disruption [24] }\end{array}$ \\
\hline \multirow[t]{2}{*}{ CD137L } & CD137 & $\begin{array}{l}\text { Atherogenic - shown by administration } \\
\text { of agonistic antibody against CD } 137 \mathrm{~L} \\
\text { and } C d 137 \text { genetically deficient mice } \\
{[23,25]}\end{array}$ & $\begin{array}{l}\text { Expression of CD137 in atherosclerotic } \\
\text { lesion [25] }\end{array}$ \\
\hline & & & $\begin{array}{l}\text { Increased sCD } 137 \text { levels in patients with } \\
\text { ACS }[26,27]\end{array}$ \\
\hline CD70 & CD27 & $\begin{array}{l}\text { Atherogenic - shown by reduced } \\
\text { atherosclerosis in } C d 70^{-} \text {Apoe } \\
\text { transgenic mice [28] }\end{array}$ & $\begin{array}{l}\text { Expression of CD70 and CD27 on T cells in } \\
\text { atherosclerotic lesions [29] }\end{array}$ \\
\hline \multirow[t]{3}{*}{ OX4OL } & OX40 & $\begin{array}{l}\text { Atherogenic - shown by administration } \\
\text { of neutralizing antibodies to OX40 } \\
\text { and Ox4Ol genetically deficient mice } \\
{[30,31,32]}\end{array}$ & $\begin{array}{l}\text { Increased expression of OX40 in patients } \\
\text { with unstable angina }\end{array}$ \\
\hline & & & $\begin{array}{l}\text { Increased sOX40 levels in patients with } \\
\text { unstable angina [33] }\end{array}$ \\
\hline & & & $\begin{array}{l}\text { Polymorphisms in TNFSF4 gene correlate } \\
\text { with myocardial infarction in women [30] }\end{array}$ \\
\hline \multirow[t]{2}{*}{ GITRL } & GITR & Uncertain & $\begin{array}{l}\text { Expression of GITR(L) in atherosclerotic pla- } \\
\text { que intima [34] }\end{array}$ \\
\hline & & & $\begin{array}{l}\text { Decreased number of GITR }{ }^{+} \text {Treg cells in } \\
\text { atherosclerotic lesions [35] }\end{array}$ \\
\hline CD30L & CD30 & $\begin{array}{l}\text { Atherogenic - shown by administration } \\
\text { of CD30L-antibody [36"'] }\end{array}$ & Inconclusive [37] \\
\hline TRAIL & TRAILR & $\begin{array}{l}\text { Atheroprotective - shown in } \\
\text { Trail-deficient mice }[38,39]\end{array}$ & $\begin{array}{l}\text { Expressed in human atherosclerotic } \\
\text { plaque and lower sTRAIL levels in coron- } \\
\text { ary disease patients }[40,41]\end{array}$ \\
\hline
\end{tabular}

ACS, acute coronary syndrome; GITR, glucocorticoid-induced TNFR-related protein; sTRAIL, soluble TRAIL; TNFRSF, tumor necrosis factor receptor superfamily; TNFSF, tumor necrosis factor superfamily; TRAIL, TNF-related apoptosis-inducing ligand; TRAILR, TRAIL receptor.

interactions mediate T-cell activation, proliferation and cytokine secretion required for B-cell activation. CD40 is constitutively expressed on APCs, including dendritic cells and B cells on which its expression is required for humoral immune responses such as proliferation and isotype switching [16,50]. CD40 has two distinct binding sites for TRAF: a proximal site for TRAF1/2/3/5 and a distal site for TRAF6 binding [51]. TRAF6 activation is linked to NFkB, Signal Transducer and Activators of Transcription 3 and protein kinase B activation [52]. TRAF1/2/3/5 activates the $\mathrm{NF \kappa B}, \mathrm{MAPK} / \mathrm{p} 38$ and c-Jun $\mathrm{N}$-terminal kinases (JNK) pathways [43].

It is important to recall that CD40/CD40L is expressed on numerous plaque-related cells, such as macrophages, platelets and dendritic cells, in addition to lymphocytes. Various studies showed that $\mathrm{Apoe}^{-/-} / \mathrm{Cd}_{40 \mathrm{I}^{-/-}}$mice, as well as anti-CD40L antibody-treated $\mathrm{Ldlr}^{-/-}$or $A p o e^{-/-}$develop reduced atherosclerosis and/or a plaque phenotype that shows a reduction in inflammation, reminiscent of stable atherosclerotic plaques in humans [18-30]. The effect of CD40L on atherosclerosis appeared hematopoietic cell-independent, as shown by

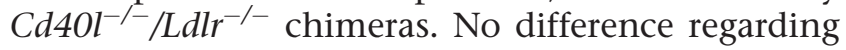
plaque size and phenotype was observed in these mice [53]. However, the contribution of the different CD40L-expressing hematopoietic cell-types still needs to be confirmed using conditional knock-out mice. Platelet CD40L is atherogenic, and plays a major role in platelet-leukocyte aggregation and leukocyte recruitment to the endothelium [16].

$\mathrm{Cd} 4 \mathrm{O}^{-/-} / \mathrm{Apoe}^{-/-}$mice, as well as $\mathrm{Cd} 4 \mathrm{O}^{-/-} / \mathrm{Ldlr}^{-/-}$ chimeras show reduced atherosclerosis and develop 
atherosclerotic plaques that contain less inflammatory cells and more fibrosis [54]. In contrast, in another report, $C d 40^{-/-} / \mathrm{Ldlr}^{-/-}$mice fed with a high-cholesterol diet for 8 and 16 weeks develop atherosclerotic lesions comparable in size with $\mathrm{Ldlr}^{-/-}$mice [55]. The main pathway mediating the proatherogenic role of CD40 in atherosclerosis is the major histocompatibility complex (MHC)IIrelated CD40-TRAF6 pathway. Mice with deficient CD40-TRAF6 signaling in $\mathrm{MHCII}^{+}$cells developed little atherosclerosis, owing to reduced leukocyte recruitment and polarization towards $\mathrm{Ly} 6 \mathrm{C}^{\text {low }}$ monocytes and M2 macrophages. In contrast, mice with deficient CD40-TRAF2/3/5 signaling in $\mathrm{MHCII}^{+}$cells showed no reduction in atherosclerosis [54].

Polymorphisms in the CD40 gene $(-1 \mathrm{C} / \mathrm{T})$ correlate with unstable coronary plaques, whereas the $\mathrm{C}$ allele frequency increased risk of coronary plaque disruption in 699 patients [24]. Moreover, several studies showed that sCD40L in the circulation is highly correlated with cardiovascular risk in humans, but its biological function remains to be elucidated until today $[23,56,57]$.

\section{CD27/CD70}

CD27/TNFRSF7 is constitutively expressed on T cells and its expression increases upon cell activation. CD27 has also been identified on B cells, hematopoietic progenitors and natural killer cells. CD27 ligand, known as CD70 or TNFSF7, is transiently expressed on activated T cells, activated B cells and dendritic cells. The downstream signaling of CD27 is mediated by TRAF2 and TRAF5, activating the NFкB and JNK signaling pathways; CD70 ligation triggers PI3K/Akt and MEK/extracellular-signal-regulated kinases (ERK)/MAPK activation [17",58].

Ligation of $\mathrm{T}$ cell CD27 to B cell CD70 has a bidirectional effect. On the one hand, it increases long-lasting T-cell survival in both primary and memory responses, and the expansion of $\mathrm{TH} 1$ IFN $\gamma$-secreting effector T cells $\left[1^{*}, 59\right]$. On the other hand, CD70 triggering on B cells impairs the formation of IgG antibodies, but not of IgM [17"]. CD27 ligation on $\mathrm{B}$ cells promotes cell proliferation and cell cycle entry [60]. It is further upregulated during germinal centre formation but does not elevate isotype switching to atherogenic IgG [60]. In addition, CD27 on B cells ligates to CD70 on T cells to stimulate $\mathrm{CD}^{+} \mathrm{T}$ cells proliferation [61]. The complex interactions indicate a fine balance between CD27 and CD70 expression on $\mathrm{B}$ and $\mathrm{T}$ cells for optimal immune responses. CD27/CD70 rescues atheroprotective regulatory Foxp $3^{+} \mathrm{T}$ cells from apoptosis in the thymus $\left[62,63^{-\prime}\right]$. Moreover, antiatherogenic regulatory Foxp $3^{+} \mathrm{T}$ cells are rescued from apoptosis in the thymus by CD27/CD70 [64"']. The co-stimulatory molecules promote inflammation by impairment of the development of TH17 helper T cells, partly via JNK pathway activation by CD27.

van Olffen et al. recently showed that B cellspecific $C d 70$-transgenic mice were protected against atherosclerotic lesion development despite the increase in IFN $\gamma$ producing effector T-cells. However, this transgenic model exhibits B-cell loss and exhaustion of the naïve T-cell pool, and in atherosclerosis, develops massive monocytosis. The authors explain the observed phenotype by the increased susceptibility of monocytes from CD70-transgenic mice to apoptosis [28]. CD27 and CD70 have also been identified on lymphocytes in human plaques, suggesting a role in atherogenesis [29].

\section{OX40/OX40L}

OX40, also known as CD134 and TNFRSF4, is transiently upregulated on activated $\mathrm{CD} 4^{+} \mathrm{T}$ cells, $\mathrm{CD}^{+}$ $\mathrm{T}$ cells and memory $\mathrm{T}$ cells, and plays a role in sustained clonal expansion, cytokine secretion by effector $\mathrm{T}$ cells and homeostasis of effector and

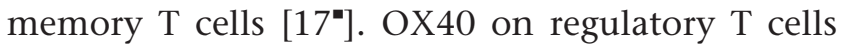
either directly inhibits their suppressive capacity or desensitizes effector $\mathrm{T}$ cells to the regulatory signal [65"']. As is true for many co-stimulatory molecules, expression of OX40 is not restricted to lymphocytes, but is also present on other cells. OX40 engages with OX40L on plaque-related cells such as mature APCs, smooth muscle cells and activated endothelial cells. OX40L can be expressed on activated T cells simultaneous with OX40, creating an amplification of the effector $\mathrm{T}$ cell responses. The intracellular signaling upon OX40 ligation has been partly elucidated in $\mathrm{CD}^{+} \mathrm{T}$ cells $\left[\mathrm{17}^{*}\right]$. Antigen recognition-independent activation depends on TRAF1, 2, 3 and 5-mediated ІкBa degradation, and subsequent $\mathrm{NF \kappa B} 1$ activation, hence migration of transcription factors p50 and RelA to the nucleus where it delivers signals for survival, proliferation and cytokine secretion, through NFATc1 activation $[33,66]$. Antigen recognition-independent activation is triggered by $\mathrm{B}$ cells and activated $\mathrm{T}$ cells. Moreover, in the antigen and TCR-dependent pathway, OX40 activates a synergizing pathway involving Akt [67].

Mice with mutation of the $O x 40 \mathrm{l}$ gene developed smaller atherosclerotic lesions compared with control animals, whereas mice overexpressing the gene develop larger lesions, indicating an atherogenic role for OX40L [30]. Nakano et al. [31] recently demonstrated that $\mathrm{Apoe}^{-/-} / \mathrm{Ox}_{40 l^{-/-}}$mice show reduced aortic atheroma compared with Apoe $^{-/-}$mice because of OX40/OX40L-dependent 
neovascularization in vasa vasorum. Moreover, similar to CD40L, the importance of vascular rather than bone marrow OX40L is shown by transplantation of $O x 40 l^{-1-}$ and wild-type bone marrow into Apoe ${ }^{-/-}$mice [31]. $\mathrm{Ldlr}^{-/-}$mice treated with an antiOX40L antibody developed reduced atherosclerotic lesions because of inhibition of the interleukin-4dependent Тн2 switch. Consequently, the levels of the atherogenic IgG1 immunoglobulin decreased, whereas those of atheroprotective oxLDL IgM titers increased. The authors found an increased interleukin-5 concentration in the serum, which is associated with IgM secretion by B1 cells rather than B2 cells [68].

The effect of the OX40/OX40L axis is further supported by the observation that patients with unstable angina showed increased OX40 expression on peripheral $\mathrm{CD}^{+} \mathrm{T}$ cells and increased soluble OX40 concentration in their circulation [33]. The rs3850641 allele of single-nucleotide polymorphism in the TNFSF4 gene is associated with the risk of myocardial infarction in women. In addition, three haplotypes of the gene are more frequent in patients with coronary artery disease [30].

\section{CD137/CD137L}

CD137/TNFRSF9/4-1BB is expressed on activated $\mathrm{T}$ cells, mainly $\mathrm{CD}^{+}$, as well as dendritic cells, natural killer cells and granulocytes. Its ligand, CD137L/TNFSF9, is constitutively expressed on B cells and dendritic cells. Ligation of CD137 and CD137L promotes T-cell expansion and proinflammatory cytokine secretion through TRAF1 and TRAF2 recruitment and downstream $\mathrm{NF \kappa B}$ and ERK signaling $[21,69,70]$.

CD137-deficient mice showed a reduction in atherosclerotic lesions because of a downregulation of proinflammatory cytokines, including IFN $\gamma$, and activation of monocytes/macrophages [71]. Similar to CD40/CD40L, the widespread expression of CD137/CD137L on various plaque-related cells, such as endothelial and smooth muscle cells, complicates the study of lymphocyte-specific atherogenic effects. However, data suggest a role for this $\mathrm{T}$ cell co-stimulator in atherogenesis, especially on $\mathrm{CD}^{+} \mathrm{T}$ cells. The strongest evidence is provided by a study from Olofsson et al. in which a CD137-agonist was administered to Apoe $e^{-/-}$mice. The atherosclerotic plaque size was only slightly larger in treated mice. The plaque phenotype, however, changed significantly and demonstrated an infiltration of $\mathrm{CD}^{+} \mathrm{T}$ cells into aortic lesion as well as increased expression of MHCII molecules. In the same study, the presence of CD137 was confirmed on T cells and endothelial cells in human atherosclerotic plaques.
Macrophages expressing CD137L are proposed to bind the endothelial cells resulting in endothelial cell activation and responses contributing to plaque aggravation [25]. Recently, $C d 137^{-/-}$knockout mice were found to develop reduced lesion sizes, initially because of decreased IFN $\gamma$ production by $\mathrm{T}$ cells. Moreover, CD137 induces the expression of TNF $\alpha$, a cytokine associated with the infiltration of leukocytes into the subendothelial space and therefore progression of atherosclerosis [71]. Studies to acute coronary syndrome patients showed elevated soluble CD137 levels in their circulation, as wells as an increased expression of CD137 on peripheral monocytes $[26,27]$.

\section{FUTURE PERSPECTIVES}

Besides lipid lowering, the importance of immune responses in atherosclerosis has emerged. The pivotal role of TNFRSF members in activation, differentiation and function of immune cells including lymphocytes allow modulation of the immune system in a highly refined manner. Targeting co-stimulatory molecules of the TNFRSF in atherosclerosis therefore will enable specific immune modulation of immune cells rather than commonly used systemic therapies, such as statins, $\beta$-blockers and lipid-lowering drugs. However, exact mechanisms of TNFRSF are still being unravelled.

So far, studies in humans and animal models confirm the immune modulatory role for several TNFRSF members in atherogenesis. Especially CD40/CD40L, OX40/OX40L, CD27/CD70 and CD137/CD137L interactions have been studied as potential targets for immune modulation in vascular disease. Interestingly, each co-stimulatory dyad modulates the immune system during atherogenesis in its own way. CD40/CD40L predominantly affects macrophage and $\mathrm{T}$ cell recruitment, activation and polarization, with the CD40-TRAF6 pathway as the dominant pathway in atherosclerosis. OX40 augments $\mathrm{TH} 2$-mediated isotype switching, resulting in increased IgG1 and decreased IgM antibodies against oxLDL in hyperlipidemic conditions. The CD27/CD70 axis fine-tunes the optimal B and T-cell responses, and affects $\mathrm{T}$ helper cell development, whereas CD137 activation results in increased CD8 ${ }^{+}$ cell infiltration in atherosclerotic plaques.

On the contrary, many key issues remain to be elucidated. In which stage of the disease the individual TNF(R)SF members exert their function, and how they interact with another, is not clear. The widespread expression of TNFRSF members beyond lymphocytes complicates clarification of the celltype-specific TNFRSF members and their intercellular interactions in atherosclerosis. Studies in 
cell-type-specific (conditional) knock-out animals are therefore eagerly awaited. Moreover, downstream signaling pathways have not been fully elucidated. Initial data regarding CD40-TRAF signaling have shown that signaling pathways are highly dependent on cell type and type of disease.

On the contrary, once the cell and disease-type specific (inter)actions of the different TNFRSF members have been unravelled, and their signaling pathways have been elucidated, therapeutic applications in atherosclerosis will be feasible and have a high possibility of being successful. In addition, TNFRSF can be utilized as reliable biomarkers for risk estimation of cardiovascular events, as soluble factors correlate with cardiovascular risk.

\section{CONCLUSION}

In this review, we have described the diverse actions of the different co-stimulatory molecules in atherosclerosis. Co-stimulatory molecules have a great potential to become therapeutic targets to treat or halt the progression of cardiovascular diseases, as they are strong modulators of the immune system, a key feature they also show in atherosclerosis. By mediating the immune system toward a modulatory function by either blocking complete or cell-type specific co-stimulatory pathways, or signaling intermediates in the co-stimulatory pathways, atherosclerosis development or its progression could be halted. However, caution must be applied to prevent immunosuppressive complications.

\section{Acknowledgements}

This research was supported by the Humboldt Foundation (Sofja Kovalevskaja grant to E.L.), the Netherlands Organization for Scientific Research, NWO (VICI grant to E.L.), the Dutch Heart Foundation (Dr E. Dekker Established Investigator grant to E.L), the AMC (AMC fellowship to E.L.), the DFG (FOR809, SFB1054 to E.L.).

\section{Conflicts of interest}

There are no conflicts of interest.

\section{REFERENCES AND RECOMIMENDED \\ READING}

Papers of particular interest, published within the annual period of review, have been highlighted as:

- of special interest

n. of outstanding interest

1. Andersson J, Libby P, Hansson GK. Adaptive immunity and atherosclerosis. Clin Immunol 2010; 134:33-46.

2. Lichtman $A H$, Binder $\mathrm{CJ}$, Tsimikas $\mathrm{S}$, et al. Adaptive immunity in atherogenmis: new insights and therapeutic approaches. J Clin Invest 2013; 123:2736.

This is an excellent review describing the newest insights of the adaptive immune system in the pathogenesis of atherosclerosis.
3. Libby P. Inflammation in atherosclerosis. Arterioscler Thromb Vasc Biol 2012; - 32:2045-2051.

This is an excellent overview of the role of inflammation in atherosclerosis.

4. Zhou X, Nicoletti A, Elhage R, et al. Transfer of CD4(+) T cells aggravates atherosclerosis in immunodeficient apolipoprotein $\mathrm{E}$ knockout mice. Circulation 2000; 102:2919-2922.

5. Elhage R, Gourdy P, Brouchet L, et al. Deleting TCR alpha beta+ or CD4+ $T$ lymphocytes leads to opposite effects on site-specific atherosclerosis in female apolipoprotein E-deficient mice. Am J Pathol 2004; 165:20132018.

6. Klingenberg R, Lebens $M$, Hermansson $A$, et al. Intranasal immunization with an apolipoprotein B-100 fusion protein induces antigen-specific regulatory $T$ cells and reduces atherosclerosis. Arterioscler Thromb Vasc Biol 2010; 30:946-952.

7. Weih F, Grabner R, Hu D, et al. Control of dichotomic innate and adaptive immune responses by artery tertiary lymphoid organs in atherosclerosis. Front Physiol 2012; 3:226.

8. Kyaw T, Tay C, Krishnamurthi S, et al. B1 a B lymphocytes are atheroprotective by secreting natural IgM that increases IgM deposits and reduces necrotic cores in atherosclerotic lesions. Circ Res 2011; 109:830-840.

9. Chou MY, Fogelstrand L, Hartvigsen K, et al. Oxidation-specific epitopes are dominant targets of innate natural antibodies in mice and humans. J Clin Invest $2009 ; 119: 1335-1349$.

10. Ait-Oufella $H$, Herbin $O$, Bouaziz JD, et al. B cell depletion reduces the development of atherosclerosis in mice. J Exp Med 2010; 207:1579-1587.

11. Kyaw $T$, Tay $C$, Khan A, et al. Conventional B2 B cell depletion ameliorates whereas its adoptive transfer aggravates atherosclerosis. J Immunol 2010; 185:4410-4419.

12. Lappalainen J, Lindstedt $K A$, Oksjoki R, et al. OxLDL-lgG immune complexes induce expression and secretion of proatherogenic cytokines by cultured human mast cells. Atherosclerosis 2011; 214:357-363.

13. Montecucco F, Vuilleumier N, Pagano $S$, et al. Anti-Apolipoprotein A-1 autoantibodies are active mediators of atherosclerotic plaque vulnerability. Eur Heart J 2011; 32:412-421.

14. Perry HM, Bender TP, McNamara CA. B cell subsets in atherosclerosis. Front Immunol 2012; 3:373.

15. Smith-Garvin JE, Koretzky GA, Jordan MS. T cell activation. Annu Rev Immunol 2009; 27:591-619.

16. Lievens D, Eijgelaar WJ, Biessen EA, et al. The multifunctionality of CD40L and its receptor CD40 in atherosclerosis. Thromb Haemost 2009; 102:206214.

17. Antunes RF, Kaski JC, Dumitriu IE. The role of costimulatory receptors of the

- tumour necrosis factor receptor family in atherosclerosis. J Biomed Biotechnol 2012; 2012:464532.

This is a good review on co-stimulation in atherosclerosis.

18. Lutgens E, Gorelik L, Daemen MJ, et al. Requirement for CD154 in the progression of atherosclerosis. Nat Med 1999; 5:1313-1316.

19. Mach F, Schonbeck U, Sukhova GK, et al. Reduction of atherosclerosis in mice by inhibition of CD40 signalling. Nature 1998; 394:200-2003.

20. Schonbeck U, Sukhova GK, Shimizu K, et al. Inhibition of CD40 signaling limits evolution of established atherosclerosis in mice. Proc Natl Acad Sci U S A 2000; 97:7458-7463.

21. Saoulli K, Lee SY, Cannons JL, et al. CD28-independent, TRAF2-dependent costimulation of resting T cells by 4-1BB ligand. J Exp Med 1998; 187:18491862.

22. Mach F, Schonbeck U, Sukhova GK, et al. Functional CD40 ligand is expressed on human vascular endothelial cells, smooth muscle cells, and macrophages: implications for CD40-CD40 ligand signaling in atherosclerosis. Proc Natl Acad Sci U S A 1997; 94:1931-1936.

23. Aukrust $P$, Muller $F$, Ueland $T$, et al. Enhanced levels of soluble and membranebound CD40 ligand in patients with unstable angina. Possible reflection of $T$ lymphocyte and platelet involvement in the pathogenesis of acute coronary syndromes. Circulation 1999; 100:614-620.

24. Wang $C$, Yan J, Yang $P$, et al. The relationship between CD40 gene polymorphism and unstable coronary atherosclerotic plaques. Clin Cardiol 2010; 33:E55-E60.

25. Olofsson PS, Soderstrom LA, Wagsater D, et al. CD137 is expressed in human atherosclerosis and promotes development of plaque inflammation in hypercholesterolemic mice. Circulation 2008; 117:1292-1301.

26. Dongming $L$, Zuxun $L$, Liangjie $X$, et al. Enhanced levels of soluble and membrane-bound CD137 levels in patients with acute coronary syndromes. Clin Chim Acta 2010; 411:406-410.

27. Yan J, Wang $C$, Chen $R$, et al. Clinical implications of elevated serum soluble CD137 levels in patients with acute coronary syndrome. Clinics (Sao Paulo) 2013; 68:193-198.

28. van Olffen RW, de Bruin $A M$, Vos $M$, et al. CD70-driven chronic immune activation is protective against atherosclerosis. J Innate Immun 2010; 2:344352.

29. de Boer OJ, Hirsch F, van der Wal AC, et al. Costimulatory molecules in human atherosclerotic plaques: an indication of antigen specific T lymphocyte activation. Atherosclerosis 1997; 133:227-234.

30. Wang $\mathrm{X}$, Ria M, Kelmenson PM, et al. Positional identification of TNFSF4, encoding OX40 ligand, as a gene that influences atherosclerosis susceptibility. Nat Genet 2005; 37:365-372. 
31. Nakano $M$, Fukumoto $Y$, Satoh $K$, et al. OX40 ligand plays an important role in the development of atherosclerosis through vasa vasorum neovascularization. Cardiovasc Res 2010; 88:539-546.

32. van Wanrooij EJ, van Puijvelde GH, de Vos $P$, et al. Interruption of the Tnfrsf4/ Tnfsf4 (OX40/OX4OL) pathway attenuates atherogenesis in low-density lipoprotein receptor-deficient mice. Arterioscler Thromb Vasc Biol 2007; 27:204210.

33. Yan J, Su H, Xu L, et al. OX40-OX4OL interaction promotes proliferation and activation of lymphocytes via NFATc1 in ApoE-deficient mice. PLoS One 2013; 8:e60854

34. Kim WJ, Bae EM, Kang YJ, et al. Glucocorticoid-induced tumour necrosis factor receptor family related protein (GITR) mediates inflammatory activation of macrophages that can destabilize atherosclerotic plaques. Immunology $2006 ; 119: 421-429$.

35. de Boer OJ, van der Meer JJ, Teeling $P$, et al. Low numbers of FOXP3 positive regulatory $T$ cells are present in all developmental stages of human atherosclerotic lesions. PLoS One 2007; 2:e779.

36. Foks AC, Bot I, Frodermann V, et al. Interference of the CD30-CD30L

n. pathway reduces atherosclerosis development. Arterioscler Thromb Vasc Biol 2012; 32:2862-2868.

This article describes the role of the co-stimulatory CD30-CD4OL dyad in atherosclerosis for the first time.

37. Mahmoudi MJ, Hedayat M, Rezaei N, et al. In vitro soluble CD30 levels in patients with chronic stable coronary artery disease. Iran J Allergy Asthma Immunol 2011; 10:237-242.

38. Watt V, Chamberlain J, Steiner T, et al. TRAIL attenuates the development of atherosclerosis in apolipoprotein E deficient mice. Atherosclerosis 2011; 215:348-354.

39. Di Bartolo BA, Chan J, Bennett MR, et al. TNF-related apoptosis-inducing ligand (TRAIL) protects against diabetes and atherosclerosis in Apoe -/- mice. Diabetologia 2011; 54:3157-3167.

40. Michowitz $Y$, Goldstein $E$, Roth $A$, et al. The involvement of tumor necrosis factor-related apoptosis-inducing ligand (TRAIL) in atherosclerosis. J Am Coll Cardiol 2005; 45:1018-1024.

41. Kavurma MM, Bennett MR. Expression, regulation and function of trail in atherosclerosis. Biochem Pharmacol 2008; 75:1441-1450.

42. Ha H, Han D, Choi Y. TRAF-mediated TNFR-family signaling. Curr Protoc Immunol 2009; Chapter 11:Unit11 9D.

43. Zirlik A, Bavendiek $U$, Libby $P$, et al. TRAF-1, $-2,-3,-5$, and -6 are induced in atherosclerotic plaques and differentially mediate proinflammatory functions of CD40L in endothelial cells. Arterioscler Thromb Vasc Biol 2007; 27: 1101-1107.

44. Leo $\mathrm{E}$, Welsh $\mathrm{K}$, Matsuzawa $\mathrm{S}$, et al. Differential requirements for tumor necrosis factor receptor-associated factor family proteins in CD40-mediated induction of NF-kappaB and Jun N-terminal kinase activation. J Biol Chem 1999; 274:22414-22422.

45. Polykratis $A$, van Loo $G$, Xanthoulea $S$, et al. Conditional targeting of tumor

-n necrosis factor receptor-associated factor 6 reveals opposing functions of Toll-like receptor signaling in endothelial and myeloid cells in a mouse model of atherosclerosis. Circulation 2012; 126:1739-1751.

Ths is a very good article describing the divergent role of TRAF6 signaling in endothelial vs. myeloid cells.

46. Missiou A, Kostlin N, Varo N, et al. Tumor necrosis factor receptor-associated factor 1 (TRAF1) deficiency attenuates atherosclerosis in mice by impairing monocyte recruitment to the vessel wall. Circulation 2010; 121:20332044.

47. Missiou $A$, Rudolf $P$, Stachon $P$, et al. TRAF5 deficiency accelerates atherogenesis in mice by increasing inflammatory cell recruitment and foam cell formation. Circ Res 2010; 107:757-766.

48. Hauer J, Puschner S, Ramakrishnan $P$, et al. TNF receptor (TNFR)-associated factor (TRAF) 3 serves as an inhibitor of TRAF2/5-mediated activation of the noncanonical NF-kappaB pathway by TRAF-binding TNFRs. Proc Natl Acad Sci U S A 2005; 102:2874-2879.

49. Urbich $C$, Mallat $Z$, Tedgui $A$, et al. Upregulation of TRAF-3 by shear stress blocks CD40-mediated endothelial activation. J Clin Invest 2001; 108:1451 1458.
50. Yamawaki H, Lehoux $S$, Berk BC. Chronic physiological shear stress inhibits tumor necrosis factor-induced proinflammatory responses in rabbit aorta perfused ex vivo. Circulation 2003; 108:1619-1625.

51. Pamukcu B, Lip GY, Snezhitskiy V, et al. The CD40-CD40L system in cardiovascular disease. Ann Med 2011; 43:331-340.

52. Mackey MF, Wang $Z$, Eichelberg $K$, et al. Distinct contributions of different CD40 TRAF binding sites to CD154-induced dendritic cell maturation and IL-12 secretion. Eur J Immunol 2003; 33:779-789.

53. Song $Z$, Jin R, Yu S, et al. CD40 is essential in the upregulation of TRAF proteins and NF-kappaB-dependent proinflammatory gene expression after arterial injury. PLoS One 2011; 6:e23239.

54. Bavendiek U, Zirlik A, LaClair $\mathrm{S}$, et al. Atherogenesis in mice does not require CD40 ligand from bone marrow-derived cells. Arterioscler Thromb Vasc Biol 2005; 25:1244-1249.

55. Lutgens $E$, Lievens $D$, Beckers $L$, et al. Deficient CD40-TRAF6 signaling in leukocytes prevents atherosclerosis by skewing the immune response toward an antiinflammatory profile. J Exp Med 2010; 207:391-404.

56. Zirlik A, Maier C, Gerdes $N$, et al. CD40 ligand mediates inflammation independently of CD40 by interaction with Mac-1. Circulation 2007; 115: 1571-1580.

57. Balla J, Magyar MT, Bereczki D, et al. Serum levels of platelet released CD40 ligand are increased in early onset occlusive carotid artery disease. Dis Markers 2006; 22:133-140.

58. Andre P, Nannizzi-Alaimo L, Prasad SK, et al. Platelet-derived CD4OL: the switch-hitting player of cardiovascular disease. Circulation 2002; 106:896899.

59. Denoeud J, Moser M. Role of CD27/CD70 pathway of activation in immunity and tolerance. J Leukoc Biol 2011; 89:195-203.

60. Arens R, Tesselaar K, Baars PA, et al. Constitutive CD27/CD70 interaction induces expansion of effector-type T cells and results in IFNgamma-mediated B cell depletion. Immunity $2001 ; 15: 801-812$.

61. Arens $R$, Nolte $M A$, Tesselaar $K$, et al. Signaling through $C D 70$ regulates $B$ cell activation and IgG production. J Immunol 2004; 173:3901-3908.

62. Munitic I, Kuka M, Allam A, et al. CD70 deficiency impairs effector CD8 T cell generation and viral clearance but is dispensable for the recall response to lymphocytic choriomeningitis virus. J Immunol 2013; 190:1169-1179.

63. Coquet JM, Middendorp S, van der Horst G, et al. The CD27 and CD70

- costimulatory pathway inhibits effector function of $T$ helper 17 cells and attenuates associated autoimmunity. Immunity 2013; 38:53-65.

This is an excellent paper describing the link between the CD27-CD70 dyad and TH17 responses.

64. Klingenberg R, Gerdes N, Badeau RM, et al. Depletion of FOXP3 + regulatory

- T cells promotes hypercholesterolemia and atherosclerosis. J Clin Invest 2013; 123:1323-1334.

This is an outstanding article on the link between Tregs and hyperlipidemia.

65. Coquet JM, Ribot JC, Babala N, et al. Epithelial and dendritic cells in the

I. thymic medulla promote CD4+Foxp3+ regulatory T cell development via the CD27-CD70 pathway. J Exp Med 2013; 210:715-728.

This is an excellent article on the link between the CD27-CD70 pathway and Treg development.

66. Vu MD, Xiao X, Gao W, et al. OX40 costimulation turns off Foxp3+ Tregs. Blood 2007; 110:2501-2510.

67. Song J, So T, Croft M. Activation of NF-kappaB1 by OX40 contributes to antigen-driven T cell expansion and survival. J Immunol 2008; 180:7240-7248.

68. So $T$, Choi $H$, Croft $M$. OX40 complexes with phosphoinositide 3-kinase and protein kinase B (PKB) to augment TCR-dependent PKB signaling. J Immunol $2011 ; 186: 3547-3555$

69. Arch $\mathrm{RH}$, Thompson $\mathrm{CB} .4-1 \mathrm{BB}$ and $\mathrm{O} \times 40$ are members of a tumor necrosis factor (TNF)-nerve growth factor receptor subfamily that bind TNF receptorassociated factors and activate nuclear factor kappaB. Mol Cell Biol 1998; 18:558-565.

70. Sabbagh L, Pulle G, Liu Y, et al. ERK-dependent Bim modulation downstream of the 4-1BB-TRAF1 signaling axis is a critical mediator of CD8 T cell survival in vivo. J Immunol 2008; 180:8093-8101.

71. Jeon $\mathrm{HJ}$, Choi JH, Jung $\mathrm{IH}$, et al. CD137 (4-1BB) deficiency reduces atherosclerosis in hyperlipidemic mice. Circulation 2010; 121:1124-1133. 